\title{
The Recycling of Sugarcane Fiber/Polypropylene Composites
}

\author{
Rosineide Miranda Leão ${ }^{*}$, Sandra Maria da Luz ${ }^{b}$, José Alexander Araújo ${ }^{a}$, Andre Luis Christoforo \\ ${ }^{a}$ Departamento de Engenharia Mecânica, Faculdade de Tecnologia, Universidade de Brasília - UnB, \\ Brasilia, DF, Brazil \\ ${ }^{b}$ Faculdade UnB Gama, Universidade de Brasília - UnB, Brasília, DF, Brazil \\ ${ }^{c}$ Departamento de Engenharia Civil, Universidade Federal de São Carlos - UFSCar, \\ São Carlos, SP, Brazil
}

Received: August 27, 2014; Revised: June 29, 2015

\begin{abstract}
Mechanical recycling is utilized to reuse waste and obtain other plastic products via the reprocessing of a material in industrial equipment. Natural fiber composites have become more popular in recent years; however, these composites' mechanical behavior remains less well-understood than single polymers' behavior after recycling. Therefore, the objective of this work was to study the degradation of different sugarcane fibers/polypropylene composites using new grinding and injection processes and to evaluate the mechanical properties of these materials using analysis of variance (ANOVA). This work reveals the mechanical behaviors of recycled natural fiber composites that contain thermal stabilizer additives. Polypropylene composites reinforced with differently treated bagasse and straw fibers (10 and $20 \mathrm{wt} \% / \mathrm{PP}$ ) were obtained through melt mixing using a high-intensity thermokinetic mixer and were subsequently injected. The recycled composites exhibited decreased tensile strength relative to the original composites. However, when thermal stabilizers were added, the mechanical properties were maintained or increased, depending on the fiber and additive types.
\end{abstract}

Keywords: sugarcane fibers, polypropylene, composites, recycling

\section{Introduction}

In recent decades, a significant amount of attention has been focused on plastics recycling, primarily as it relates to the economics of vehicle recycling activities, which, together with natural fiber composites, have become more popular in industrial scenarios ${ }^{1}$; however, these composites' mechanical behavior remains less well understood than single polymers' behavior after recycling. Natural fibers, when they are adequately combined with polymers, can provide better flexibility and improve mechanical resistance and toughness ${ }^{2,3}$. In addition, in contrast to synthetic fiber recycling, natural fibers composite recycling is more environmentally sustainable ${ }^{4}$.

Plastics are widely used in many applications, such as the polypropylene that is widely used in the automotive industry ${ }^{1}$. Consequently, the amount of waste that is generated is increasing and causing environmental problems. The recycling of materials and the replacement of traditional composites with less environmentally harmful alternatives have become more important. New environmental policies are noticeably stricter. Research on new materials has consequently intensified, and industrial competition for economical materials that preserve the environment has resulted in the use of natural fibers for plastic reinforcement $t^{1,5,6}$.

Most of the polymeric materials that are currently in use are thermoplastics; this classification includes plastics that soften and flow for molding or manipulation when the temperature and pressure are modulated. When the heat and

*e-mail: rosemirandaleao@gmail.com pressure are removed, these plastics solidify and acquire the shape of the mold cavity. The re-application of temperature and pressure can restart the process, thereby rendering these materials recyclable ${ }^{7-10}$. Mechanical recycling is the most widespread form of recycling and is commonly used to recycle plastics industrially ${ }^{8}$. Mechanical recycling reuses waste to obtain another plastic product via reprocessing of the polymeric materials in industrial equipment ${ }^{9}$.

Mechanical recycling is a physical method of recycling. Depending on the material, the type of process and the presence of additives, the mechanical properties can be maintained. This process involves a number of operations, including the separation of plastics by resin-type, washing to remove dirt and contaminants, grinding and crushing to reduce the plastics particle size, extrusion by heat, and reprocessing into new plastic goods. This type of recovery is mainly restricted to thermoplastics because thermosets cannot be remolded by the application of heat ${ }^{9,10}$.

The recycling of polypropylene (PP) is one example of polymer recycling ${ }^{8}$. The main driving force behind the increased recycling of post-consumer PP is its widespread use, particularly in the automotive industry ${ }^{1}$. The recyclability of natural fibers composite materials is important for maintaining this material as a sustainable product, even after its end of life. Therefore, some works in the literature have considered this approach in composite material development and studies ${ }^{11-15}$. In this context, the use of thermal stabilizer additives for composite materials presents potential for improving their performance and technological aspects for this material ${ }^{1,15}$. 
According to Luz et al. ${ }^{15}$, the use of an additive maintained or even increased the tensile strength of the original composite relative to that of the recycled composite without additives. Importantly, these reprocessed composites were subjected to additional mixing by using a high-intensity thermokinetic mixer. Although this process typically results in excessive breakdown and thermal degradation, the use of additives prevented these outcomes. In a recent work that used lignin as an additive in polypropylene/coir composites, the authors also concluded that the additive incorporation did not decrease the mechanical strength ${ }^{11}$.

The influence of thermal stabilizers as additives in composites was recently studied by Hamad et al. ${ }^{16}$. In this study, polypropylene composites reinforced with differently treated natural fibers $(10$ and $20 \mathrm{wt} \% / \mathrm{PP})$ were obtained through melt mixing using a high-intensity thermokinetic mixer and were subsequently injected. The recycled composites exhibited decreases in tensile strength relative to the original composites. Therefore, when thermal stabilizers were added, the mechanical properties were maintained or increased, depending on the fiber and additive types.

In another study proposed by Bourmaud \& Baley ${ }^{17}$, although the $\mathrm{PP} /$ hemp and $\mathrm{PP} /$ sisal composites provided an important strength enhancement in relation to pure PP, recycling did not induce any change in the tensile strength value for the PP/hemp composite, but there was a significant decrease after 7 cycles for the PP/sisal composite. Similarly, Rowell et al. ${ }^{18}$ studied the recyclability of polypropylene composites that were reinforced with jute and observed that the tensile and flexural strengths were not significantly affected during nine reprocessing attempts.

Most single polymer plastics made from petroleum are relatively easy to recycle. The properties of some waste plastics are similar to those made from virgin materials. The number of products manufactured from waste plastics is increasing, including wood plastic composites. Wood plastic composites with wood fiber/flour have also gained popularity due to the low cost of recycled wood ${ }^{19}$.

In this work, sugarcane fiber composites were obtained and subjected to mechanical recycling. Sugarcane fibers are a renewable resource; the use of natural fibers may promote good mechanical properties, low abrasion, low energy consumption during preparation and lower costs compared with synthetic fibers. We have published several reports related to these fiber types ${ }^{20,21}$. Different types of fibers have been used, including sugarcane bagasse, cellulose from bagasse, and sugarcane straw.

The objective of this work was to study the degradation of these composite materials using new grinding and injection processes and to evaluate the mechanical properties of these materials using analysis of variance (ANOVA). This study investigates the effects of the treatment, fiber content, and thermal stabilizer additives.

\section{Experimental}

\subsection{Composites preparation in a thermokinetic mixer and injection molding processing}

Sugarcane bagasse was furnished by Edras Ecosystems (classified as B3 (10 mm) and medulla), and the sugarcane straw was provided by Ester Power Stations, which is located in Cosmopolis - SP (Brazil). The chemical composition of the sugarcane bagasse was cellulose: $43 \%$; hemicellulose: $28 \%$; and lignin: $22 \%$. For sugarcane straw (15 mm length), the composition was cellulose: $40 \%$; hemicellulose: $30 \%$; and lignin: $25 \%$. The polypropylene composites were processed as $50 \mathrm{~g}$ batches in a thermokinetic mixer (model $\mathrm{MH}-50 \mathrm{H}$ ) at $5250 \mathrm{rpm}$. This equipment consists of a chamber with a two-part capsule, in which the fiber and polypropylene composites are prepared. The heat is generated by the kinetic energy of the high speed of the blades. In this process, fiber is incorporated into the melted polymer. When the polymer melts completely (at approximately 190 to $205^{\circ} \mathrm{C}$ ), it comes into contact with the blades, thereby increasing the amperage and indicating the end of the process. Further, the milled composite is molded as a tensile specimen using injection molding equipment (model JASOT IJ 300/130 ton) at $205^{\circ} \mathrm{C}$. The composites were reinforced with 10 and $20 \mathrm{wt} \%$ of different fiber types: bagasse in nature (BNT), bagasse pretreated with hot water (BPT), bagasse cellulose (CBT), and straw in nature (PNT). The different processes used to obtain the composites were TI - thermokinetic mixing and injection molding of the original composites and $\mathrm{R}$ - thermokinetic mixing and injection molding for mechanical recycling. For mechanical recycling, the composites were milled and submitted to thermokinetic mixing with or without $0.5 \mathrm{wt} \%$ of thermal stabilizer additives (based on mixed metal salt blends): Hostanox ${ }^{\circledR} \mathrm{P}-\mathrm{EPQ}^{\circledR}$ powder from Clariant ${ }^{\circledR}(\mathrm{Cla})$ or Gotalube GL-4519 from Gotalube ${ }^{\circledR}$ (Go).

\subsection{Mechanical recycling of composites}

The tensile properties of the original and recycled composites were obtained, and the tensile strength $\left(\mathrm{R}_{\mathrm{t}}\right)$ and maximum tensile strain through elongation $\left(\mathrm{El}_{\text {max }}\right)$ were investigated. The composites were analyzed in an "Instron" universal-testing machine (model 4301) that was equipped with pneumatic claws. In the tensile tests, five specimens of the composites were analyzed with dimensions in agreement with the ASTM D638 ${ }^{22}$ standard: $13 \mathrm{~mm}$ width, $160 \mathrm{~mm}$ length and $2.7 \mathrm{~mm}$ thickness with a $2 \mathrm{~mm} \mathrm{~min}^{-1}$ crosshead speed.

\subsection{Statistical analysis}

The experimental conditions were evaluated separately by treatment type to generate four types of reinforcement (BNT, BPT, CBT, and PNT), as illustrated in Table 1.

Analysis of variance was used to verify the influence among the mechanical properties for the different composites (fiber type, fiber content and additive type). The investigated factors, which were the BNT treatment fraction (10 and $20 \mathrm{wt} \%$ ) and the processing method (TI, R; Cla, Go), produced a $2^{1} 4^{1}$ full-factorial design, thereby providing eight distinct experimental conditions. The factors and experimental levels for BPT, CBT, and PNT led to $2^{2}, 2^{2}$, and $2^{1} 2^{2}$ designs and generated four, four, and eight different sets of experimental conditions, respectively. ANOVA was used to evaluate the influence of the treatment and processing on the variables of interest using the Minitab ${ }^{\circledR} 17$ software.

\section{Results and Discussion}

We performed the mechanical recycling process by reprocessing the original composites. As described in the Experimental section, the composites were ground and subsequently injected. Both the original and recycled composites 
Table 1. Experimental conditions studied per group.

\begin{tabular}{|c|c|c|c|c|}
\hline $\mathbf{C}$ & BNT & BPT & CBT & PNT \\
\hline $\mathrm{C} 1$ & BNT $10 \mathrm{wt} \% / \mathrm{PP}$ - TI & BPT $10 \mathrm{wt} \% / \mathrm{PP}$ - TI & CBT $10 w t \% / P P-T I$ & PNT $10 \mathrm{wt} \% / \mathrm{PP}$ - TI \\
\hline $\mathrm{C} 2$ & BNT 20 wt\%/PP - TI & BPT $20 \mathrm{wt} \% / \mathrm{PP}$ - TI & CBT 20 wt $\% / P P$ - TI & PNT $20 \mathrm{wt} \% / \mathrm{PP}$ - TI \\
\hline $\mathrm{C} 3$ & BNT $10 w t \% / P P ~-~ R ~$ & 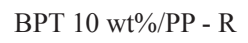 & CBT $10 w t \% / P P-R$ & PNT $10 \mathrm{wt} \% / \mathrm{PP}$ - Cla \\
\hline $\mathrm{C} 4$ & BNT 20 wt $\% / P P$ - R & 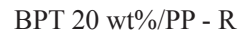 & CBT 20 wt $\% / P P-R$ & PNT $20 \mathrm{wt} \% / \mathrm{PP}$ - Cla \\
\hline $\mathrm{C} 5$ & BNT 10 wt $\% / \mathrm{PP}$ - Cla & & & PNT $10 \mathrm{wt} \% / \mathrm{PP}$ - Go \\
\hline $\mathrm{C} 6$ & BNT $20 w t \% / P P-C l a ~$ & & & PNT $20 \mathrm{wt} \% / \mathrm{PP}$ - Go \\
\hline $\mathrm{C} 7$ & BNT $10 \mathrm{wt} \% / \mathrm{PP}$ - Go & & & \\
\hline $\mathrm{C} 8$ & BNT $20 \mathrm{wt} \% / \mathrm{PP}$ - Go & & & \\
\hline
\end{tabular}

TI - thermokinetic mixing and injection molding of the original composites; $\mathrm{R}$ - thermokinetic mixing and injection molding for mechanical recycling; Cla additive: thermokinetic mixing $+0.5 \mathrm{wt} \%$ of Clariant ${ }^{\circledR}$ for mechanical recycling; Go additive: thermokinetic mixing $+0.5 \mathrm{wt} \%$ of Gotalube ${ }^{\circledR}$ for mechanical recycling.

were darkly colored. This mixing process has a shearing effect and is aggressive to the fibers ${ }^{23,24}$, thus significantly decreasing their dimensions. During the preparation and reprocessing of the composites, a mild, sweet odor was released, which was most likely due to the caramelization of the cellulose fibers ${ }^{23,24}$.

The most commonly used molding processes to obtain the plastic parts are extrusion, injection, blow and thermoforming. These processes generally involve the application of heat and pressure. To minimize the damage, the recycling process uses additives provided by Clariant ${ }^{\circledR}$ and Gotalube ${ }^{\circledR}$. These additives are thermal stabilizers based on mixed metal salt blends. The additives provide more environmental protection for engineering thermoplastics, such as polyamides, polypropylene and polyesters. These additives were used in a proportion of $0.5 \%(\mathrm{w} / \mathrm{w})$ of the composite.

Table 2 shows the results for the tensile strength as a function of fiber content. These results show that the fiber addition influenced this property, especially for composites reinforced with cellulose from bagasse. According to Table 2, with the presence of additive, there was a maintenance or increase of the tensile strength compared with the original composites that were recycled without the use of additives. In general, the bagasse fiber composites exhibited higher strength and elongation values than did sugarcane straw fibers composites.

In general, the original composites obtained had similar tensile strengths to PP alone (mostly reinforced with fibers $10 \mathrm{wt} \%$ ). This finding reveals that even with the inclusion of a reasonable amount by weight of fiber (volume due to the low density of fibers -0.7 g. $\mathrm{cm}^{-3}$ ) in the PP, the resulting composite material remained tough (similar to PP alone) $)^{14,25-27}$. These data thus justify the replacement of part of the PP with raw material from renewable natural sources, generating savings compared with pure polymer for a particular component, without losing tensile mechanical properties. With recycling, the tensile strength is $13 \%$ less than for material prepared using CBT/PP. The other materials showed virtually no change in relation to the tensile strength. The addition of fibers caused failure between the fiber and matrix, and this failure could cause a rupture, thereby decreasing the elongation at break. Hence, a high fiber content can cause higher failure; consequently, elongation is anticipated.

Inside bagasse composites, CBT systems result in tougher and rigid materials with up to $15 \mathrm{wt} \%$ fibers, followed by BNT, which presents better properties at $20 \mathrm{wt} \%$.
Table 2. Results of the investigation of the tensile strength $\left(R_{t}\right)$ and maximum tensile strain through elongation $\left(\mathrm{El}_{\max }\right)$.

\begin{tabular}{ccc}
\hline Experimental Conditions & $\mathbf{R}_{\mathbf{t}}$ (MPa) & EI $_{\max }$ (mm) \\
\hline PP & $26.9 \pm 1.3$ & $11.0 \pm 0.1$ \\
C1A (BNT 10 wt\%/PP - TI) & $26.3 \pm 0.2$ & $8.9 \pm 0.7$ \\
C2A (BNT 20 wt\%/PP - TI) & $24.8 \pm 0.1$ & $6.4 \pm 0.2$ \\
C3A (BNT 10 wt\%/PP - R) & $25.7 \pm 0.4$ & $9.0 \pm 0.1$ \\
C4A (BNT 20 wt\%/PP - R) & $25.0 \pm 0.2$ & $7.2 \pm 0.3$ \\
C5A (BNT 10 wt\%/PP - Cla) & $27.9 \pm 0.3$ & $8.0 \pm 0.1$ \\
C6A (BNT 20 wt\%/PP - Cla) & $26.6 \pm 0.2$ & $7.0 \pm 0.4$ \\
C7A (BNT 10 wt\%/PP - Go) & $27.3 \pm 0.1$ & $8.1 \pm 0.3$ \\
C8A (BNT 20 wt\%/PP - Go) & $25.8 \pm 0.4$ & $7.0 \pm 0.2$ \\
C1B (BPT 10 wt\%/PP - TI) & $27.0 \pm 0.7$ & $8.7 \pm 0.2$ \\
C2B (BPT 20 wt\%/PP - TI) & $26.0 \pm 0.2$ & $6.0 \pm 0.5$ \\
C3B (BPT 10 wt\%/PP - R) & $25.3 \pm 0.3$ & $9.2 \pm 0.2$ \\
C4B (BPT 20 wt\%/PP - R) & $27.6 \pm 0.3$ & $6.4 \pm 0.3$ \\
C1C(CBT 10 wt\%/PP - TI) & $30.0 \pm 0.6$ & $7.1 \pm 0.3$ \\
C2C (CBT 20 wt\%/PP - TI) & $26.4 \pm 0.3$ & $8.1 \pm 0.2$ \\
C3C (CBT 10 wt\%/PP - R) & $26.5 \pm 0.1$ & $7.4 \pm 0.1$ \\
C4C (CBT 20 wt\%/PP - R) & $26.8 \pm 0.2$ & $6.0 \pm 0.5$ \\
C1D (PNT 10 wt\%/PP - TI) & $25.8 \pm 0.3$ & $10.3 \pm 0.6$ \\
C2D (PNT 20 wt\%/PP - TI) & $25.0 \pm 0.1$ & $7.0 \pm 0.2$ \\
C3D (PNT 10 wt\%/PP - Cla) & $25.2 \pm 0.9$ & $7.8 \pm 0.9$ \\
C4D (PNT 20 wt\%/PP - Cla) & $26.0 \pm 0.2$ & $6.3 \pm 0.1$ \\
C5D (PNT 10 wt\%/PP - Go) & $26.6 \pm 0.5$ & $9.6 \pm 0.4$ \\
C6D (PNT 20 wt\%/PP - Go) & $26.7 \pm 0.2$ & $7.2 \pm 0.1$ \\
\hline
\end{tabular}

The highest values for tensile strength were obtained using the $\mathrm{C} 1$ (CBT $10 \mathrm{wt} \% / \mathrm{PP}$ - TI) conditions; the values were, on average, $11.52 \%$ greater than the tensile strength of neat polypropylene. For this composite, mechanical recycling decreased the mechanical strength. The insertion of the fibers reduced the maximum tensile strain through elongation under all of the investigated conditions relative to that of neat PP. The PNT $10 \mathrm{wt} \% / \mathrm{PP}$ - TI conditions produced the highest values, whereas the C4 (CBT $20 \mathrm{wt} \% / \mathrm{PP}$ - R) conditions produced the lowest values $(6.40 \%$ and $45.50 \%$ less, respectively, than did the maximum tensile strain through elongation of the reference sample (PP)).

Table 3 displays the ANOVA results for the experimental conditions for BNT, BPT, CBT, and PNT during the evaluation of the mechanical properties. P-values less than or equal to $0.05(5 \%)$ indicate $95 \%$ significance ${ }^{26}$. The results are 
presented alongside their corresponding determination coefficients $\left(\mathrm{R}^{2}\right)$.

In the ANOVA, it was assumed that both samples were extracted from independent populations and could be described by a normal distribution ${ }^{19}$. The Anderson-Darling normality test was conducted; normality was established for the investigated responses because the $\mathrm{P}$-values were greater than 0.05 in all cases and varied between 0.216 and $0.749^{27,28}$.

The results shown in Table 3 indicate that the individual factors and their interactions were significant for the BNT material mechanical properties because the P-values in every case were less than 0.05 . Figures $1 \mathrm{a}$ and $1 \mathrm{~b}$ display the interaction plots between the significant factors for the BNT materials' tensile strength and the maximum tensile strain through elongation, respectively ${ }^{28}$.

The composites prepared with BNT $10 \mathrm{wt} \% / \mathrm{PP}$ exhibited superior tensile strengths compared with the materials that were prepared with $20 \mathrm{wt} \% / \mathrm{PP}$ in every process studied

Table 3. ANOVA with different types of fibers and treatments.

\begin{tabular}{|c|c|c|c|c|}
\hline \multirow{2}{*}{ BNT } & \multicolumn{2}{|c|}{$\mathbf{R}_{t}$ (MPa) } & \multicolumn{2}{|c|}{$\mathbf{E} \mathbf{l}_{\max }(\mathbf{m m})$} \\
\hline & P-value & $\mathbf{R}^{2}$ & P-value & $\mathbf{R}^{2}$ \\
\hline BNT fraction & 0.000 & $76 \%$ & 0.000 & $86 \%$ \\
\hline Processing & 0.000 & & 0.003 & \\
\hline BNT fraction $\times$ Processing & 0.000 & & 0.001 & \\
\hline \multirow{2}{*}{ BPT } & \multicolumn{2}{|c|}{$\mathbf{R}_{\mathrm{t}}(\mathrm{MPa})$} & \multicolumn{2}{|c|}{$\mathbf{E I}_{\max }(\mathbf{m m})$} \\
\hline & P-value & $\mathbf{R}^{2}$ & P-value & $\mathbf{R}^{2}$ \\
\hline BPT fraction & 0.003 & $84 \%$ & 0.000 & $79 \%$ \\
\hline Processing & 0.643 & & 0.038 & \\
\hline BPT fraction $\times$ Processing & 0.000 & & 0.009 & \\
\hline \multirow{2}{*}{ CBT } & \multicolumn{2}{|c|}{$\mathbf{R}_{\mathrm{t}}(\mathrm{MPa})$} & \multicolumn{2}{|c|}{$\mathrm{El}_{\max }(\mathbf{m m})$} \\
\hline & P-value & $\mathbf{R}^{2}$ & P-value & $\mathbf{R}^{2}$ \\
\hline CBT fraction & 0.000 & $81 \%$ & 0.374 & $86 \%$ \\
\hline Processing & 0.000 & & 0.001 & \\
\hline CBT fraction $\times$ Processing & 0.000 & & 0.001 & \\
\hline \multirow{2}{*}{ PNT } & \multicolumn{2}{|c|}{$\mathbf{R}_{\mathrm{t}}(\mathrm{MPa})$} & \multicolumn{2}{|c|}{$\mathbf{E l}_{\max }(\mathbf{m m})$} \\
\hline & P-value & $\mathbf{R}^{2}$ & P-value & $\mathbf{R}^{2}$ \\
\hline PNT fraction & 0.406 & $78 \%$ & 0.000 & $73 \%$ \\
\hline Processing & 0.000 & & 0.000 & \\
\hline PNT fraction $\times$ Processing & 0.000 & & 0.000 & \\
\hline
\end{tabular}

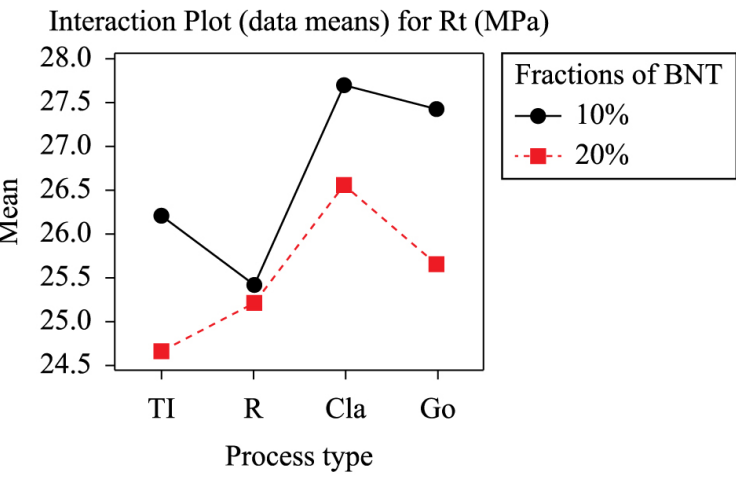

(a)
(Figure 1a). The highest values were achieved with the material prepared using BNT $10 \mathrm{wt} \% / \mathrm{PP}$ and the Cla process, whereas the lowest values were obtained with the material prepared using BNT $20 \mathrm{wt} \% / \mathrm{PP}$ and the TI process. Similarly, the highest tensile strength and greatest maximum elongation were exhibited by materials that were prepared with BNT $10 \mathrm{wt} \% / \mathrm{PP}$ and the R process, whereas the lowest values were exhibited by the material prepared using BNT $20 \mathrm{wt} \% / \mathrm{PP}$ and the TI process. These results show that the Clariant additive presents the best results in both cases. However, the best mechanical properties for a fiber content of $10 \mathrm{wt} \%$ show that the bagasse is not a good reinforcement at a high fiber content. In this case, the bagasse was not treated.

Figure 2 shows a plot of the major factors and their interactions during the experimental process in which BPT was used to study the tensile strength and maximum tensile strain through elongation ${ }^{28}$.

The BPT with $20 \mathrm{wt} \% / \mathrm{PP}$ composite exhibited superior tensile strength compared with BPT $10 \mathrm{wt} \% / \mathrm{PP}$ (Figure $2 \mathrm{a}$ ). In this case, the bagasse was treated with hot water and interacted better with the matrix. The interactions between the factors revealed that the composites of BNT with $20 \mathrm{wt} \% / \mathrm{PP}$ prepared using the $\mathrm{R}$ process gave the best results; the tensile strengths were $9 \%$ greater than those of the materials prepared with BPT $10 \mathrm{wt} \% / \mathrm{PP}$. When the maximum tensile strain through elongation was studied, the use of BPT with $20 \mathrm{wt} \% / \mathrm{PP}$ resulted in a material with a lower tensile strength (Figure 2c): 17.84\% less than the tensile strength of the material prepared using BPT $10 \mathrm{wt} \% / \mathrm{PP}$. Among the investigated processes, the $\mathrm{R}$ treatment process provided the best results: the tensile strengths were $5.80 \%$ greater than those of materials prepared using the TI process (Figures 2b and d). Figure 3 shows a plot of the major factors and their interactions during the investigation of the mechanical properties of the materials prepared using $\mathrm{CBT}^{28}$.

The highest values for tensile strength were obtained with CBT $10 \mathrm{wt} \% / \mathrm{PP}$ and the TI process (Figure $3 \mathrm{a}$ ); these values were $13.80 \%$ higher than those of materials prepared with CBT and $20 \mathrm{wt} \% / \mathrm{PP}$ using the same process. With respect to the maximum tensile strain through elongation, the highest values were obtained with CBT $20 \mathrm{wt} \% / \mathrm{PP}$ and the TI process (Figures $3 \mathrm{~b}$ and $3 \mathrm{c}$ ). Figure 4 shows a plot of the main factors and their interactions during the investigation of

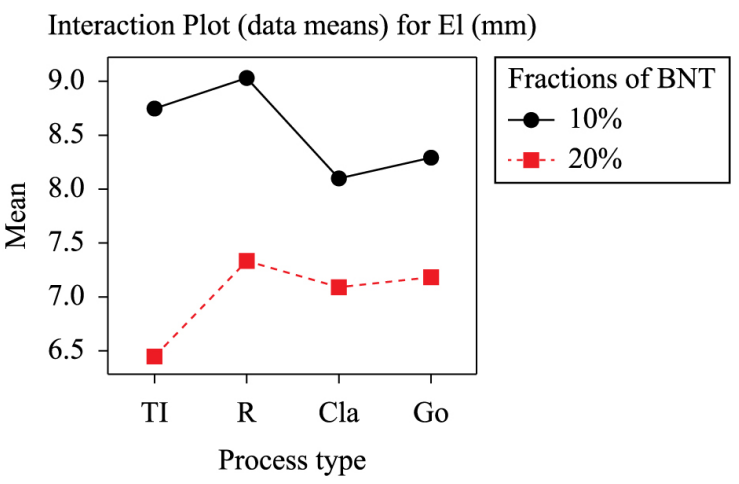

(b)

Figure 1. Interactions between the major influences (BNT) on (a) tensile strength and (b) maximum tensile strain through elongation. 


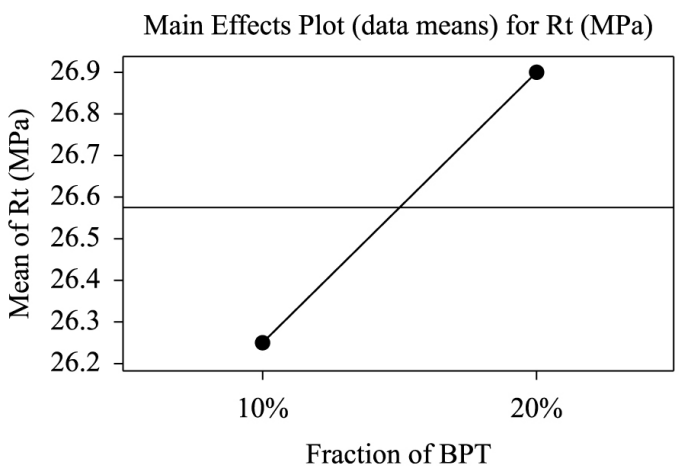

(a)

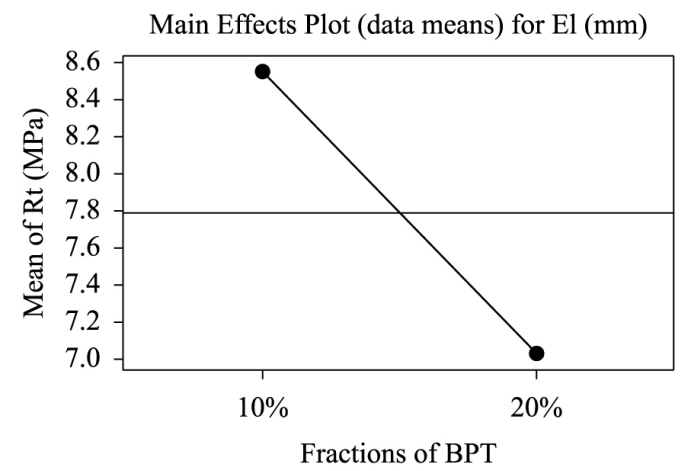

(c)

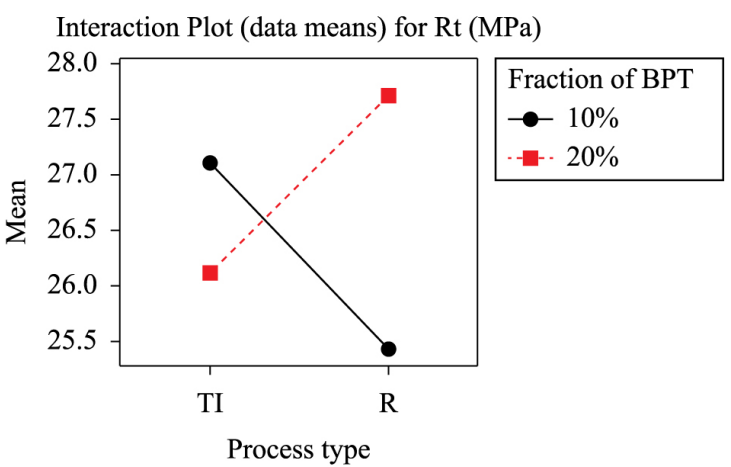

(b)

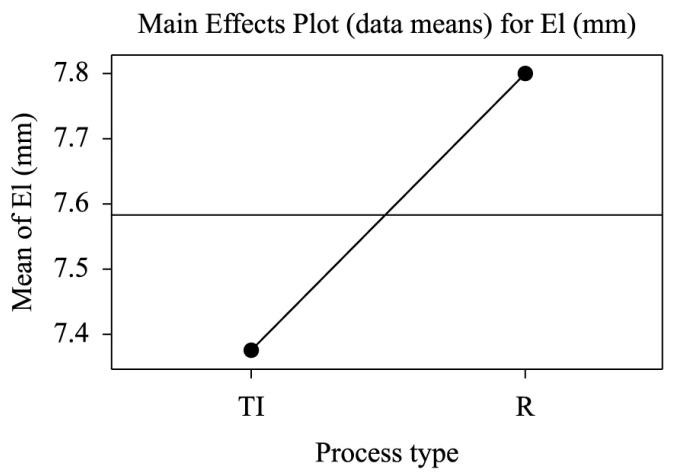

(d)

Figure 2. Major factors and their interactions (BPT) for (a, b) tensile strength and (b, c) maximum tensile strain through elongation.

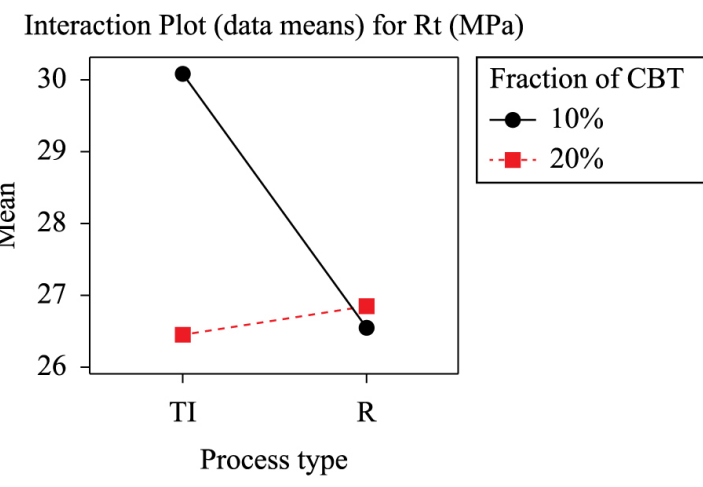

(a)

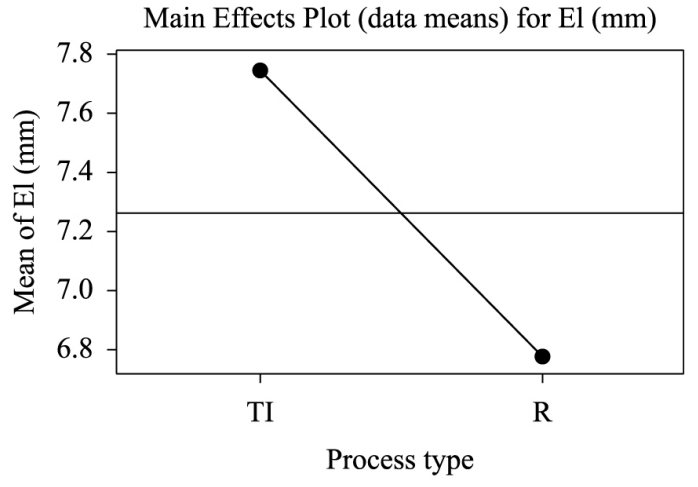

(b)

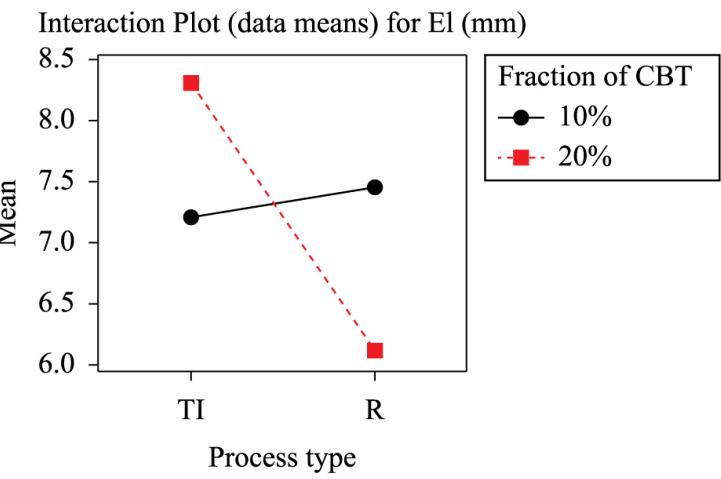

(c)

Figure 3. Major factors and their interactions (CBT) for (a) tensile strength and (b, c) maximum tensile strain through elongation. 


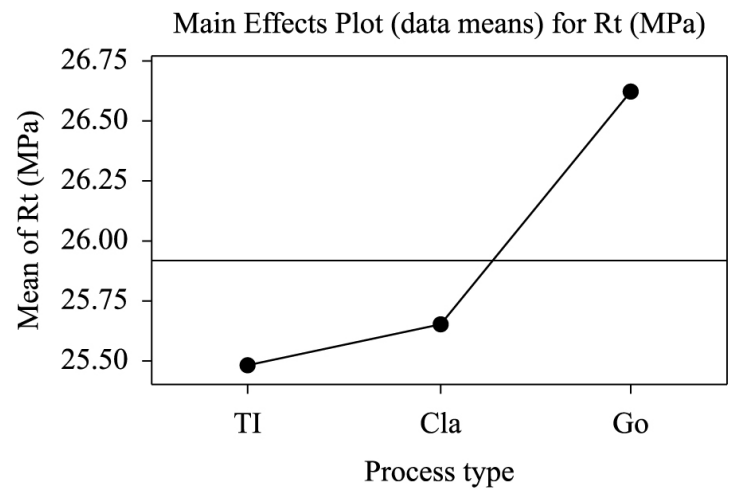

(a)

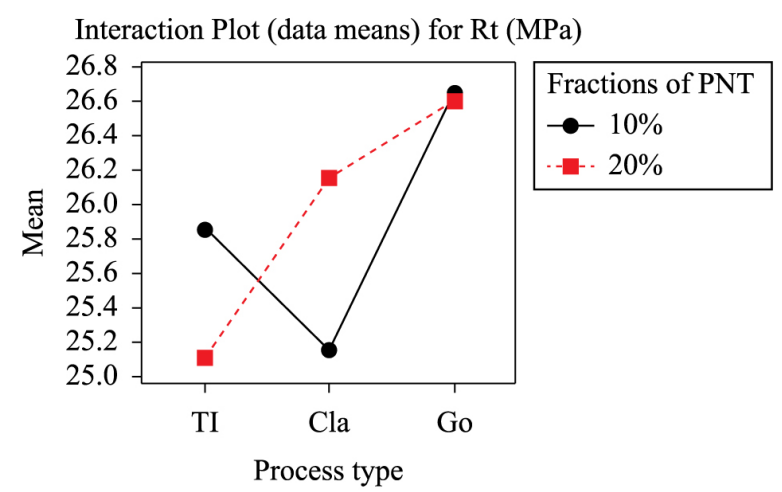

(b)

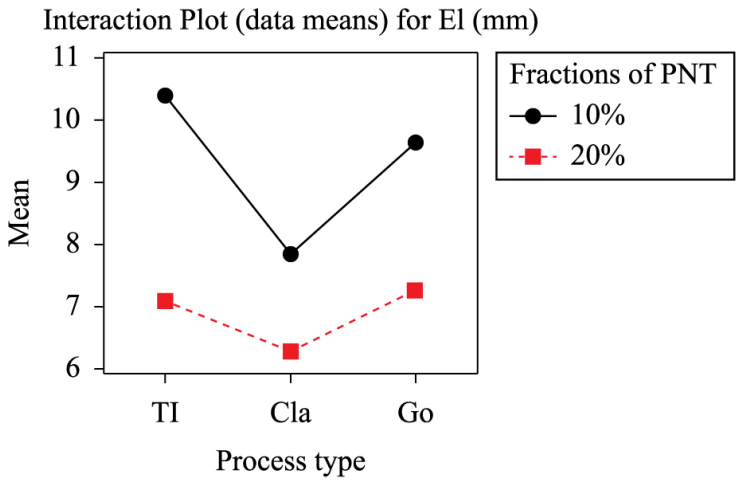

(c)

Figure 4. Major factors and their interactions (PNT) for (a, b) tensile strength and (c) maximum tensile strain through elongation.

the tensile strength and the maximum tensile strain through the elongation of materials prepared using PNT.

The highest values for tensile strength were achieved with the Go process (Figure $2 \mathrm{a}$ ) and PNT with 10 or $20 \mathrm{wt} \% / \mathrm{PP}$ (Figures $4 \mathrm{a}$ and $4 \mathrm{~b}$ ). With respect to the maximum tensile strain through elongation, the use of PNT with $10 \mathrm{wt} \% / \mathrm{PP}$ yielded superior results (Figure $4 \mathrm{c}$ ). The best results for the material prepared using PNT $10 \mathrm{wt} \% / \mathrm{PP}$ and the TI process were $47.50 \%$ higher than those of materials made with PNT $20 \mathrm{wt} \% / \mathrm{PP}$ and the same treatment process. As mentioned by Second Bourmaud \& Baley ${ }^{17}$, the recycling of composites induces a slight decrease in the tensile modulus due to the decrease in molecular weight induced by reprocessing. However, with the thermal stabilizer addition, the mechanical properties are improved. In other work, Mansouri et al. found that the tensile strength of the $40 \mathrm{wt} \%$ OTF (organosolv triticale fibers) composite with $6 \mathrm{wt} \%$ of MAPE (coupling agent maleated polyethylene) increased by more than $120 \%$ compared with that of the high-density recycled polyethylene. The increase was higher than that shown by similar composite materials using polypropylene and hemp strands as reinforcement.

Hamad et al. ${ }^{16}$ investigated the mechanical behaviors of recycled natural fiber composites that contained thermal stabilizer additives. Polypropylene composites reinforced with differently treated natural fibers (10 and $20 \mathrm{wt} \% / \mathrm{PP}$ ) were obtained through melt mixing using a high-intensity thermokinetic mixer and were subsequently injected, as in our study. In this work, the mechanical properties of the recycled composites were determined for comparison with the mechanical properties of the original composites. The recycled composites exhibited decreased tensile strength relative to the original composites. Therefore, when thermal stabilizers were added, the mechanical properties were maintained or increased, depending on the fiber and additive types. As shown by Bourmaud et al. ${ }^{13}$, the introduction of $\mathrm{PP} /$ hemp and $\mathrm{PP} /$ sisal composites provides an important enhancement in strength relative to pure PP (33.1 \pm 0.2 vs. $23.3 \pm 0.3 \mathrm{MPa}$ and $26.1 \pm 0.4 \mathrm{MPa})$.

\section{Conclusions}

Among the manufactured materials, composites that contained (CBT $10 \mathrm{wt} \% / \mathrm{PP}$ - TI) and were prepared using the TI process exhibited the best tensile strength. Hence, the addition of treated fibers (CBT $10 \mathrm{wt} \% / \mathrm{PP}-\mathrm{TI}$ ) to the matrix resulted in composites with superior tensile strength compared with neat PP. The addition of untreated fibers (PNT $10 \mathrm{wt} \% / \mathrm{PP}$ - Go) to the matrix resulted in composites with inferior elongation compared with neat PP. With the addition of additive, there was a maintained or increased tensile strength of the composite compared with the original composite and the recycled composite without the use of additives. In general, the composites were more brittle than the matrix, and the tensile modulus indicated that the $20 \mathrm{wt} \% / \mathrm{PP}$ composites were more rigid than were neat $\mathrm{PP}$ and the other composites. As expected, the inclusion of fibers in 
the composites reduced the maximum tensile strain through elongation under all of the investigated conditions compared with the maximum elongation of the reference material (PP) because the inclusion of fibers made the manufactured material more fragile. Performing an analysis of variance per group enabled us to observe that, in general, the treatment and processing significantly affected the mechanical properties, thereby resulting in materials with different characteristics

\section{References}

1. Ferrão P and Amaral J. Assessing the economics of auto recycling activities in relation to European Union Directive on end of life vehicles. Technological Forecasting and Social Change. 2006; 73(3):277-289. http://dx.doi.org/10.1016/j. techfore.2004.03.010.

2. Beigbeder J, Perrin D, Mascaro JF and Lopez-Cuesta JM. Study of the physico-chemical properties of recycled polymers from waste electrical and electronic equipment (WEEE) sorted by high resolution near infrared devices. Resources, Conservation and Recycling. 2013; 78:105-114. http://dx.doi.org/10.1016/j. resconrec.2013.07.006.

3. Castro DPC, Dias CGBT and Faria JAF. Production and Evaluation of Recycled Polymers from Açaí Fibers. Materials Research. 2010; 13(2):159-163. http://dx.doi.org/10.1590/ S1516-14392010000200007.

4. Joshi SV, Drzal LT, Mohanty AK and Arora S. Are natural fiber composites environmentally superior to glass fiber reinforced composites. Composites. Part A, Applied Science and Manufacturing. 2004; 35(3):371-376. http://dx.doi.org/10.1016/j. compositesa.2003.09.016.

5. Abu-Sharkh BF and Hamid H. Degradation study of date palm fibre/polypropylene composites in natural and artificial weathering: mechanical and thermal analysis. Polymer Degradation \& Stability. 2004; 85(3):967-973. http://dx.doi. org/10.1016/j.polymdegradstab.2003.10.022.

6. Espert A, Vilaplana F and Karlsson S. Comparison of water absorption in natural cellulosic fibres from wood and one-year crops in polypropylene composites and its influence on their Mechanical Properties. Composites. Part A, Applied Science and Manufacturing. 2004; 35(11):1267-1276. http://dx.doi. org/10.1016/j.compositesa.2004.04.004.

7. Canevarolo SV Jr. Ciência dos polímeros: um texto básico para tecnólogos e engenheiros. São Paulo: Artliber; 2002. 183 p.

8. Bahlouli N, Pessey D, Raveyre C, Guillet J, Ahzi S, Dahoun A, et al. Recycling effects on the rheological and thermomechanical properties of polypropylene-based composites. Materials \& Design. 2012; 33:451-458. http://dx.doi.org/10.1016/j. matdes.2011.04.049.

9. Mano EB, Pacheco EBAV and Bonelli CMC. Meio ambiente, poluição e reciclagem. São Paulo: Edgar Blücher; 2005. 182 p.

10. Ylä-Mella J. Recycling of polymers. Environmental Catalysis. 2005; 9:1-9.

11. Morandim-Giannetti AA, Agnelli JAM, Lanças BZ, Magnabosco $\mathrm{R}$, Casarin $\mathrm{S}$ and Bettini SHP. Lignin as additive in polypropylene/ coir composites: Thermal, mechanical and morphological properties. Carbohydrate Polymers. 2012; 87(4):2563-2568. http://dx.doi.org/10.1016/j.carbpol.2011.11.041

12. Lope JP, Girones J, Mendez JA, Puig J and Pelach MA. Recycling Ability of Biodegradable Matrices and Their CelluloseReinforced Composites in a Plastic Recycling Stream. Journal of Polymers and the Environment. 2012; 20(1):96-103. http:// dx.doi.org/10.1007/s10924-011-0333-1.. under each set of test conditions. In addition, we conclude that the addition of thermal stabilizers helped maintain or improve the mechanical properties of the recycled composites.

\section{Acknowledgements}

The authors wish to thank FAPESP, CAPES and CNPq for their support.

13. Bourmaud A, Duigou AL and Baley C. What is the technical and environmental interest in reusing a recycled polypropylene/ hemp fibre composite. Polymer Degradation \& Stability. 2011; 96(10):1732-1739. http://dx.doi.org/10.1016/j. polymdegradstab.2011.08.003.

14. Corradini E, Ito EN, Marconcini JM, Rios CT, Agnelli JAM and Mattoso LHC. Interfacial behavior of composites of recycled poly(ethyelene terephthalate) and sugarcane bagasse fiber. Polymer Testing. 2009; 28(2):183-187. http://dx.doi. org/10.1016/j.polymertesting.2008.11.014.

15. Luz SM, Del Tio J, Rocha GJM, Gonçalves AR and Del'Arco AP Jr. Cellulose and cellulignin from sugarcane bagasse reinforced polypropylene composites: Effect of acetylation on mechanical and thermal properties. Composites. Part A, Applied Science and Manufacturing. 2008; 39(9):1362-1369. http://dx.doi.org/10.1016/j.compositesa.2008.04.014.

16. Hamad K, Kaseem M and Deri F. Recycling of waste from polymer materials: An overview of the recent works. Polymer Degradation \& Stability. 2013; 98(12):2801-2812. http://dx.doi. org/10.1016/j.polymdegradstab.2013.09.025.

17. Bourmaud A and Baley C. Investigations on the recycling of hemp and sisal fibre reinforced polypropylene composites. Polymer Degradation \& Stability. 2007; 92(6):1034-1045. http://dx.doi.org/10.1016/j.polymdegradstab.2007.02.018.

18. Rowell RM, Sanadi AR, Caulfield DF and Jacobson RE. Utilization of natural composites: problems and opportunities. In: Leão AL, Carvalho FX and Frollini E. Lignocellulosic: plastics composites. São Paulo: Universidade de São Paulo. 1997. p. 23-52.

19. Ashori A and Nourbakhsh A. Characteristics of wood-fiber plastic composites made of recycled materials. Waste Management. 2009; 29(4):1291-1295. http://dx.doi.org/10.1016/j.wasman.2008.09.012. PMid:19168343.

20. Spinacé MAS, Lambert CS, Fermoselli KKG and Paoli MA. Characterization of lignocellulosic curauá fibres. Carbohydrate Polymers. 2009; 77(1):47-53. http://dx.doi.org/10.1016/j. carbpol.2008.12.005.

21. Selke SE and Wichman I. Wood fiber/polyolefin composites. Composites. Part A, Applied Science and Manufacturing. 2004; 35(3):321-326. http://dx.doi.org/10.1016/j.compositesa.2003.09.010.

22. American Society for Testing and Materials - ASTM. ASTM D638: association standards testing material: standard test methods for tensile properties of plastics. West Conshohocken; 1988.

23. Fung KL, Xing XS, Li RKY, Tjong SC and Mai YW. An investigation on the processing of sisal fibre reinforced polypropylene composites. Composites Science and Technology. 2003; 63:1255-1258.

24. Gopakumar TG and Pagé DJYS. Compounding of nanocomposites by thermokinetic mixing. Journal of Applied Polymer Science. 2005; 96(5):1557-1563. http://dx.doi.org/10.1002/app.21597.

25. Riess M, Ernst T, Popp R, Müller B, Thoma H, Vierle O, et al. Studied analysis of flame retarded polymers and recycling 
materials. Chemosphere. 2000; 40(9-11):937-941. http://dx.doi. org/10.1016/S0045-6535(99)00336-7.

26. Liu X and Bertilsson H. Recycling of ABS and ABS/PC Blends. Journal of Applied Polymer Science. 1999; 74(3):510-515. http:// dx.doi.org/10.1002/(SICI)1097-4628(19991017)74:3<510::AIDAPP5>3.0.CO;2-6.
27. Montgomery DC. Design and analysis of experiments. 6th ed. Arizona: John Wiley \& Sons; 2005.

28. Silva LJ, Panzera TH, Silva VRV and Christoforo AL. Investigação das propriedades mecânicas de compósitos poliméricos de fibra de bananeira através do método de planejamento fatorial de experimentos. Ciência \& Tecnologia dos Materiais. 2011;23:3-4. 